\title{
COMPARATIVE ANALYSIS ON DIFFERENT FEEDING TECHNIQUES OF TEXTILE ANTENNA FOR GPS-L1 APPLICATION
}

\author{
${ }^{1}$ Anis Fariza Md. Pazil ${ }^{*}$ Nurul Huda Abd. Rahman, ${ }^{1}$ Nurulazlina Ramli, ${ }^{1}$ Noor Farhana \\ Halil Abdul Razak
}

\author{
${ }^{1}$ Centre of Advanced Electrical \& Electronic System, Faculty of Engineering, Built \\ Environment and Information Technology, SEGi University, 47810 Petaling Jaya, Selangor, \\ Malaysia \\ ${ }^{2}$ Antenna Research Centre, Faculty of Electrical Engineering, Universiti Teknologi MARA \\ 40450 Shah Alam, Selangor, Malaysia
}

* Corresponding Author: anis@ @egi.edu.my TEL: (03)-6145 1777

\begin{abstract}
This paper presents a comparative analysis of textile antenna using different feeding techniques for Global Positioning System (GPS-L1) application. Textile materials which are commonly used in the wearable application has gained much attention due to the flexibility and conformability characteristic of the antenna. Nevertheless, the flexibility of this antenna will introduce the bending and stretching element to its physical structure that may degrades the performance. To ensure the maximum power transfer takes place between the source and the antenna, a suitable feeding method must be identified. In this paper, the microstrip feedline technique and coaxial feeding technique will be studied comparatively using felt textile material as the substrate with the relative permittivity, $\varepsilon_{\mathrm{r}}$ of 1.098 and tangent loss, $\delta$ of 0.0395 . It is attached to a copper tape which act as the conductive material with thickness of $0.035 \mathrm{~mm}$. Using Computer Simulation Technology (CST) Microwave Studio software, the result will be analysed comparatively from the performance validation in return loss, gain, bandwidth, directivity and radiation pattern.
\end{abstract}

Keywords: Coaxial, Feeding Techniques, GPS, Textile Antenna, Wearable

\section{Introduction}

The emergence of 5G technology has made wearable applications popular in various industry fields such as healthcare, navigation, monitoring and many more. Being wearable, the antenna 
must carry the features of comfortability which includes lightweight and flexible element to the wearer. To ensure it demonstrates good performance, the antenna must be able to supply maximum power transfer from the source; therefore, the suitable feeding technique must be applied to avoid unwanted losses from occurring. There are many available feeding techniques which are available and popular to be integrated into the microstrip antenna such as microstrip feedline, coaxial feed, aperture-coupled feed and also proximity coupled feed (Sourabh Bisht et al, 2014). From these four feeding techniques, it is very important first to understand the design procedure and complexity of feeding techniques as textile antenna structure is a compressible material which thickness and density might change with low pressures unlike the conventional microstrip antenna (Salvado et al, 2019).

In the microstrip feedline technique shown in Figure 1, a conducting strip which is normally small is connected directly to the edge of microstrip patch antenna. This feature gives an advantage whereby the feed is allowed to be etched on the same substrate to provide a planar structure. Nevertheless, the feed radiation may occur due to the improper selection of substrate thickness used that leads to the increase of surface waves. It will further affect the efficiency and bandwidth performance as it will generate the undesired cross polarisation radiation. However, this feeding method is very popular due to its simplicity in planar structure.

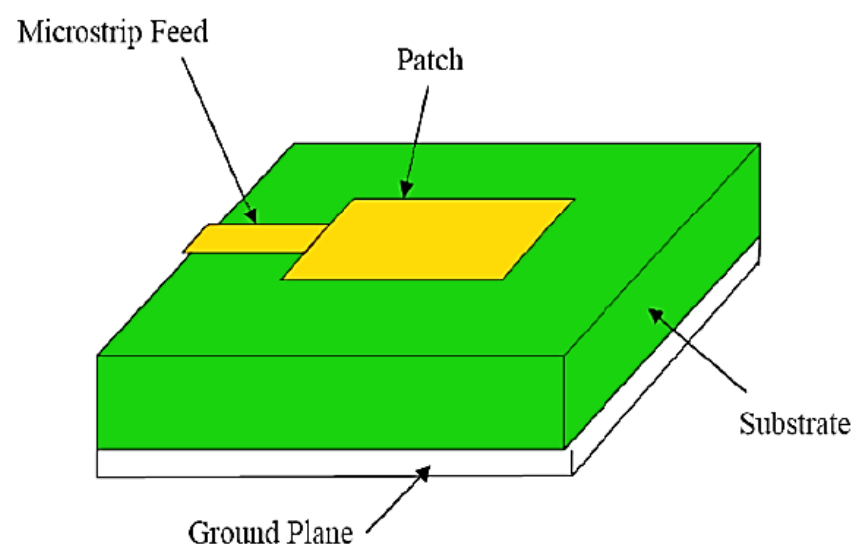

Figure 1. Microstrip feedline technique (Kumar et al, 2013)

For Figure 2 that shown the coaxial feed technique, the inner conductor of coaxial connector penetrates the dielectric to the top of the radiator and soldered while the outer conductor is connected to the ground plane of the antenna structure. This feeding method is easy to fabricate and can be placed at any desired position of the patch to obtain the impedance matching while contributes a low spurious radiation effect. In addition, this spurious feed radiation can be 
isolated with the existence of the ground plane in the structure; therefore, leads to better antenna performance.

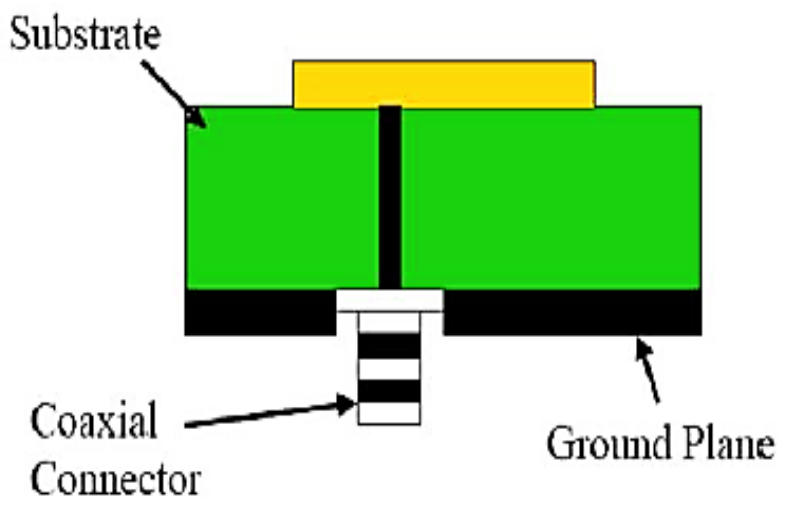

Figure 2. Coaxial Feed Technique (Kumar et al, 2013)

This paper will highlight the design of feeding techniques in comparative of microstrip feedline and coaxial feeding techniques by analysing the optimised design in both and further conclude the suitable feeding technique to be used in terms of operating frequency, gain, bandwidth, and the return loss characteristics for the desired operation of GPS application.

\section{Characterization Process}

In this work, felt textile is chosen as the antenna substrate for both feeding techniques because it has a greater thickness as compared to other available textiles in order to achieve an adequate bandwidth. Figure 3 shows the steps of characterisation for Felt textile performed in the Antenna Research Centre (ARC) in Universiti Teknologi MARA, Shah Alam, Malaysia. In this procedure, the dielectric measurement is performed using the coaxial cable and Vector Network Analyzer (VNA) with spectrum analyzer to measure the permittivity and tangent loss of felt textile. In Figure 4, the digital gauge meter is used to perform the thickness measurement of the textile.
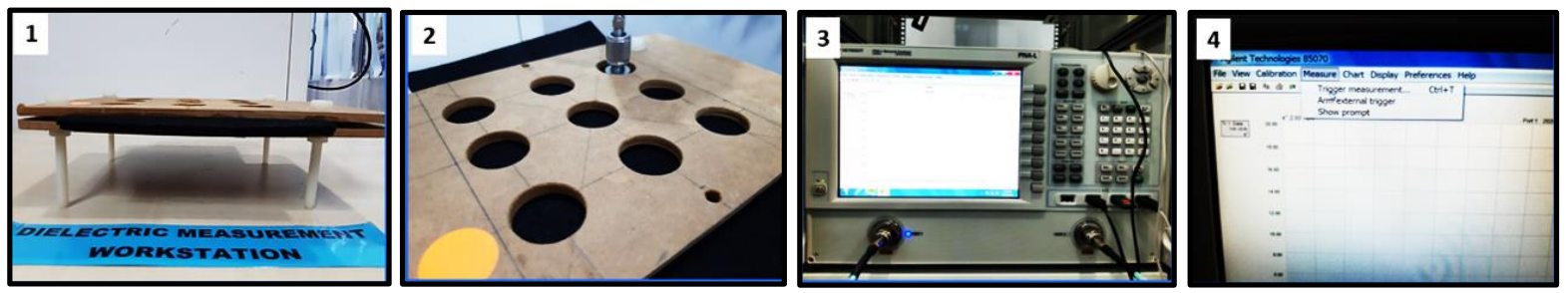

Figure 3. Characterisation process of felt textile 


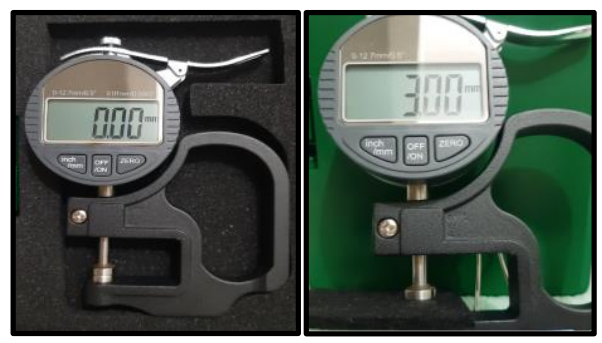

Figure 4. Thickness measurement of felt textile using digital gauge meter

From the above characterisation of Felt textile, the material possesses a thickness of $3.00 \mathrm{~mm}$ with the permittivity, $\varepsilon_{\mathrm{r}}$ of 1.098 and tangent loss, $\delta$ of 0.0395 .

\section{Methodology}

\subsection{Antenna Design}

For the design of Antenna A and Antenna B which uses microstrip feedline and coaxial probe feed respectively, the thickness of the copper tape used as a radiating element and ground plane is $0.035 \mathrm{~mm}$ with the conductivity of $5.96 \times 10^{7} \mathrm{~S} / \mathrm{m}$ and the substrate used is felt textile for both.

Figure 5 and Figure 6 show the layout of Antenna A and Antenna B for microstrip feedline and coaxial feed techniques respectively. To design the geometrical structure of both antennas, several equations were used to generate the required parameter in the design. Firstly, to calculate the rectangular patch antenna of both antenna, Equation (1) to (5) to calculate for the width ( $W p$ ) and length $(L p)$ of the patch (Balanis, 2005).

$$
\begin{gathered}
W=\frac{c}{2 f_{r} \sqrt{\frac{\left(\varepsilon_{r}+1\right)}{2}}} \\
L=L_{e f f}-2 \Delta L
\end{gathered}
$$

where,

$$
L_{e f f}=\frac{2}{2 f_{r} \sqrt{\varepsilon_{\text {reff }}}}
$$




$$
\begin{aligned}
& \Delta L=0.412 h \frac{\left(\varepsilon_{\text {reff }}+0.3\right)\left(\frac{W}{h}+0.264\right)}{\left(\varepsilon_{\text {reff }}-0.258\right)\left(\frac{W}{h}+0.8\right)} \\
& \varepsilon_{\text {reff }}=\frac{\varepsilon_{r}+1}{2}+\frac{\varepsilon_{r}-1}{2}\left(\frac{1}{\sqrt{1+12 h / W}}\right)
\end{aligned}
$$

In the equations above, the value of constant $c$ indicates the free-space velocity of electromagnetic wave $\left(3 \times 10^{8} \mathrm{~m} / \mathrm{s}\right), \varepsilon_{r}$ is the dielectric constant, $h$ is the thickness of the substrate and $f_{r}$ is resonant frequency at $1.575 \mathrm{GHz}$. Meanwhile, to demonstrate the geometrical size of ground and the substrate, the following equations are used in both design:

$$
\begin{gathered}
L s=L g=L p+6 h \\
W s=W g=W p+6 h
\end{gathered}
$$

Based on the result generated from Equations (1) to Equation (7), the design for both antennas were simulated using the Computer Simulation Technology (CST) software and further

\begin{tabular}{|c|c|c|c|c|c|c|c|c|}
\hline Parameter & $\begin{array}{c}\text { Patch } \\
\text { Length } \\
\text { (mm) }\end{array}$ & $\begin{array}{l}\text { Patch } \\
\text { Width } \\
(\mathbf{m m})\end{array}$ & $\begin{array}{c}\text { Ground } \\
\text { Length } \\
(\mathrm{mm})\end{array}$ & $\begin{array}{l}\text { Ground } \\
\text { Width } \\
\text { (mm) }\end{array}$ & $\begin{array}{c}\text { Substrate } \\
\text { Length } \\
(\mathrm{mm})\end{array}$ & $\begin{array}{c}\text { Substrate } \\
\text { Width } \\
(\mathrm{mm})\end{array}$ & $\begin{array}{c}\text { Feedline } \\
\text { Width } \\
\text { (mm) }\end{array}$ & $\begin{array}{l}\text { Probe } \\
\text { Feed } \\
\text { Point } \\
(\mathrm{X}, \mathrm{Y})\end{array}$ \\
\hline & $L p$ & $W p$ & Lg & $W g$ & $L s$ & $W s$ & $W f$ & $X f, Y f$ \\
\hline Antenna A & 86.00 & 92.99 & 105.14 & 110.99 & 105.14 & 110.99 & 13.60 & - \\
\hline Antenna B & 105.07 & 88.85 & 84.40 & 110.92 & 84.40 & 110.92 & - & $0, L p / 3$ \\
\hline
\end{tabular}
optimised to achieve the resonant frequency operation at $1.575 \mathrm{GHz}$. The following dimensions is proposed in Table 1 for Antenna A and Antenna B.

Table 1. Dimension of the Optimised Design for Antenna A and Antenna B 


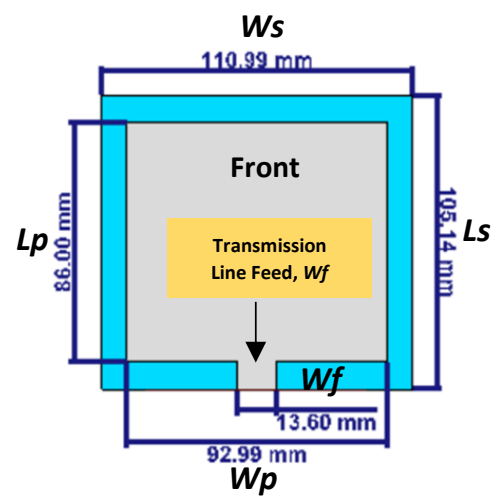

(a)

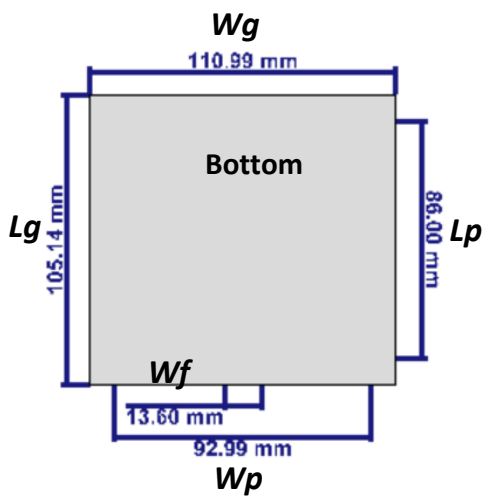

(b)

Figure 5. Microstrip feedline technique on Antenna A (a) Front and bottom layout (b) Cross sectional view

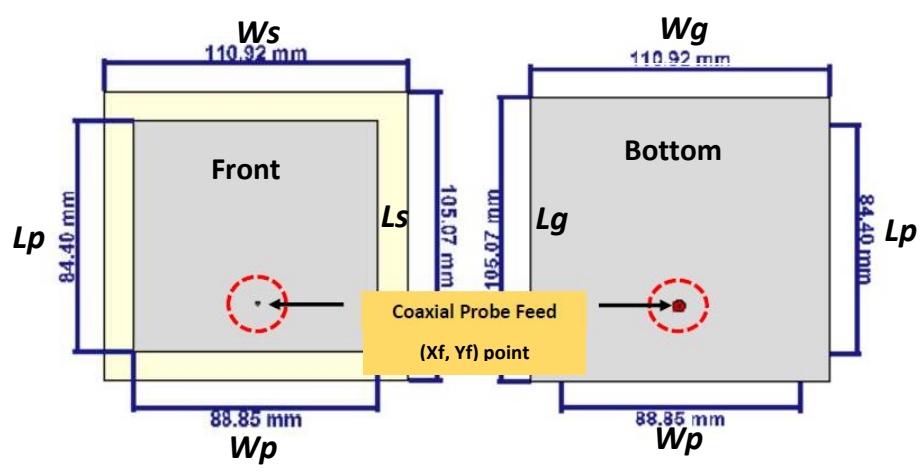

(a)

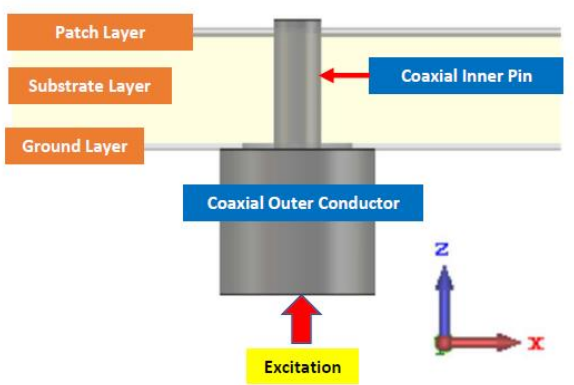

(b)

Figure 6. Coaxial feeding technique on Antenna B (a) Front and bottom layout (b) Cross sectional view

\subsection{Feeding Techniques Optimization}

To achieve the matching impedance, $Z_{c}$ of the feed line in Antenna A, the width of the feed line, $W_{0}$ is obtained by adjusting Equation (8) to match the expected characteristic impedance of 50 ohm (Balanis, 2005). In Antenna A, the optimised value obtained from the calculated equation of $W_{0}$ is $13.60 \mathrm{~mm}$ to meet the 50 -ohm impedance.

$$
Z_{c}= \begin{cases}\frac{60}{\sqrt{\epsilon_{\text {reff }}} \ln \left[\frac{8 h}{W_{0}}+\frac{W_{0}}{4 h}\right]} & \frac{W_{0}}{h} \leq 1 \\ \frac{120 \pi}{\sqrt{\epsilon_{\text {reff }}}\left[\frac{W_{0}}{h}+1.393+0.667 \ln \left(\frac{W_{0}}{h}+1.444\right)\right]} & \frac{W_{0}}{h}>1\end{cases}
$$


Meanwhile, the feeding point location for the coaxial feed technique can be located at the point of $(X f, Y f)$ in the $\mathrm{x}-\mathrm{y}$ coordinates of the antenna. Equations (9) and (10) are used as references to achieve a good match between the transmission line and the port (S.E Jasim, 2015).

$$
\begin{gathered}
X_{f}=\frac{L}{\sqrt[2]{\varepsilon_{\text {reff }}}} \\
Y_{f}=\frac{W}{2}
\end{gathered}
$$

Nevertheless, the calculation value arrived at the point in which the location is at the edge of the antenna that is more suitable for the transmission line feed. Therefore, this point has been optimised by point re-location and subsequently yielded the 50 -ohm impedance at the point of probe feed of $X f=0$ and $Y f=L p / 3$.

\section{Result and discussion}

\subsection{Simulated Results}

Figure 7 shows the result of return loss $\left(S_{11}\right)$ for the optimised Antenna A and Antenna B designs. From these figures, both Antenna A and Antenna B resonate at $1.575 \mathrm{GHz}$ with the magnitude of reflection coefficient (S11) equal to $-12.42 \mathrm{~dB}$ and $-20.41 \mathrm{~dB}$ respectively. In Figure 7(a), the $-10 \mathrm{~dB}$ bandwidth is achieved is $4.3 \%$ (from $1.5409-1.6092 \mathrm{GHz}$ ) having almost equal performance with the bandwidth in Antenna A in Figure 7(b) that is from 1.5410 to $1.6092 \mathrm{GHz}$.

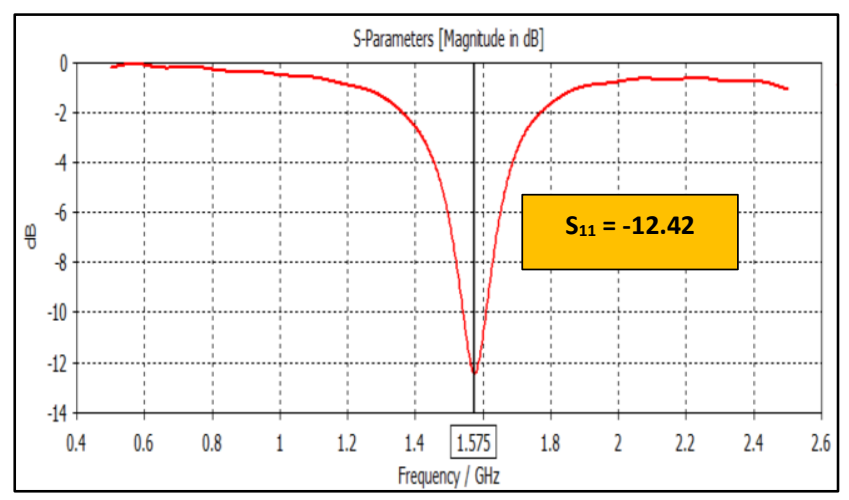

(a)

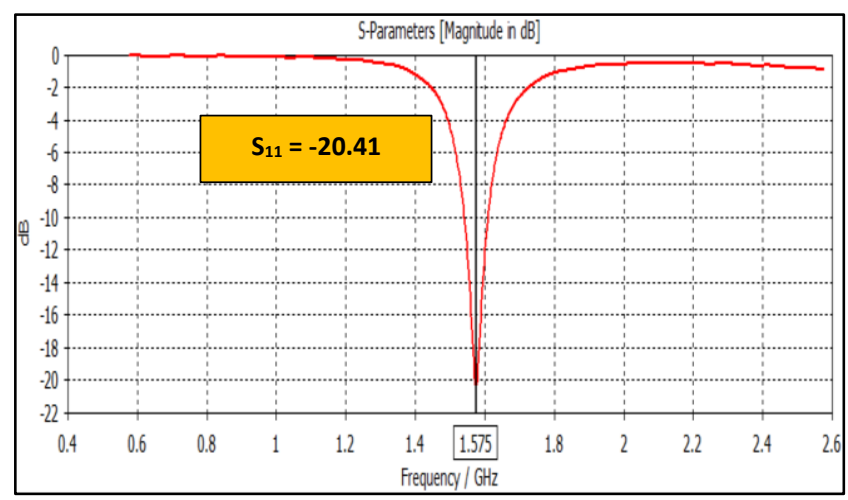

(b)

Figure 7. Return loss $\left(S_{11}\right)$ of simulated result for (a) Antenna A (b) Antenna B 
As observed in Figure 8, the realized gain for Antenna B (Figure 8b) is 54\% higher than Antenna B; that is $4.41 \mathrm{dBi}$ as compared to Antenna A (Figure 8a) at only $2.87 \mathrm{dBi}$. This is due to Antenna B has more directive radiation pattern result as compared to Antenna B.

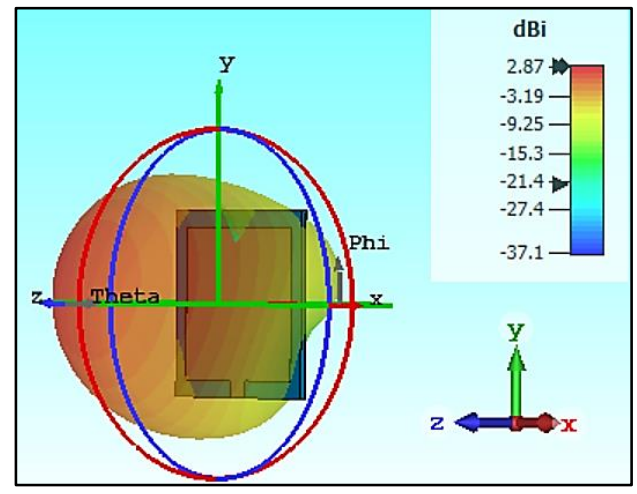

(a)

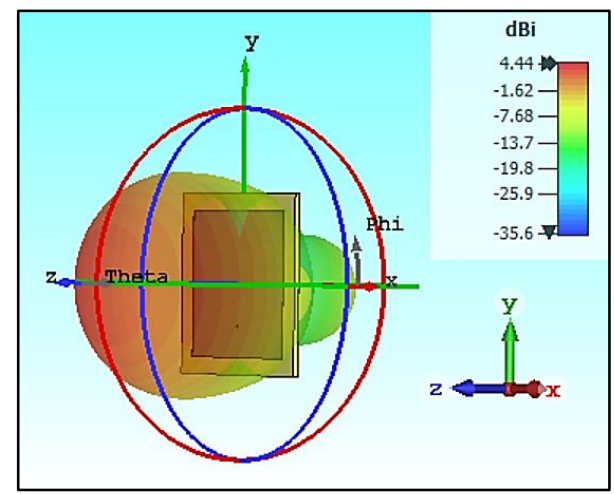

(b)

Figure 8. Gain plot of the simulated result for (a) Antenna A (b) Antenna B

The simulated $\mathrm{E}$ and $\mathrm{H}$-plane far-field radiation pattern at resonant frequency of $1.575 \mathrm{GHz}$ are presented in Figure 9. The radiation pattern in Antenna B is observe as more directional as shown in Figure 9(c) and Figure 9(d) yielding $8.66 \mathrm{dBi}$ in the directivity radiation pattern.

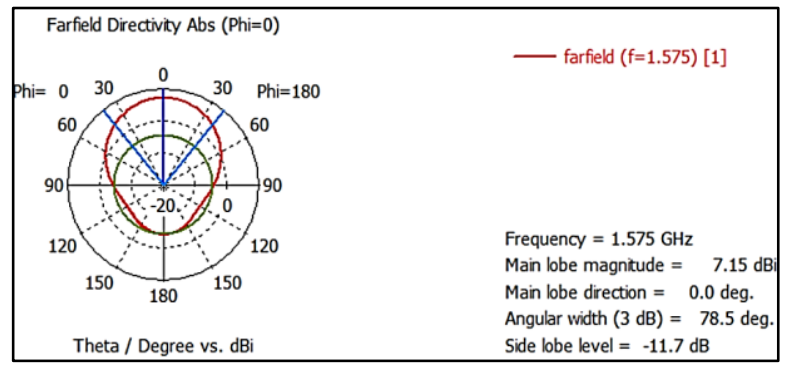

(a)

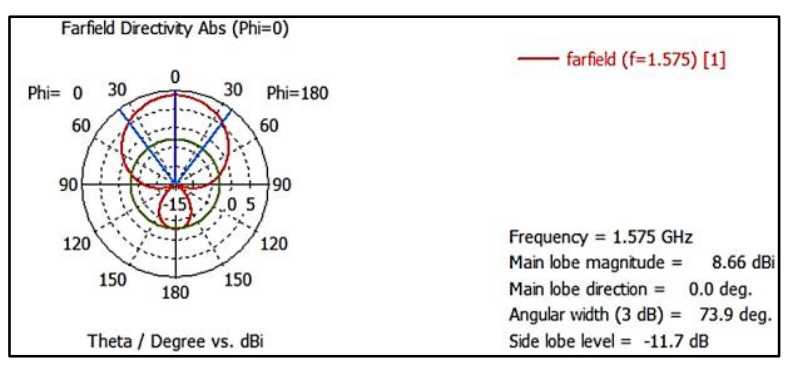

(c)

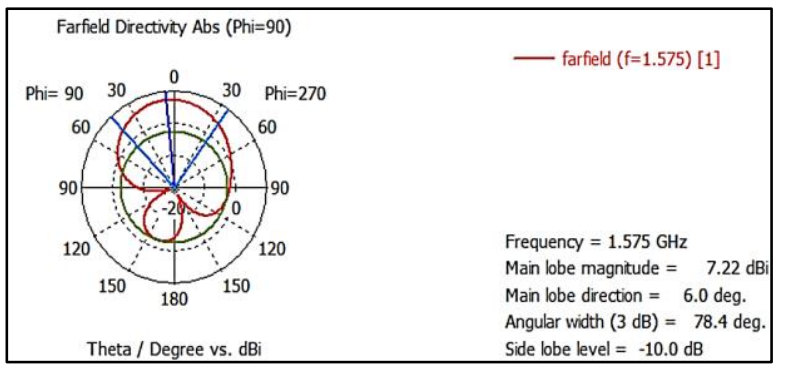

(b)

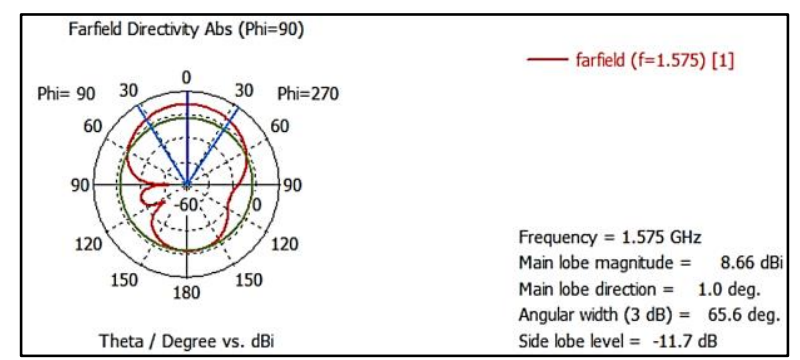

(d)

Figure 9. Radiation pattern for Antenna A (a) E- plane $\left(\mathrm{Phi}=0^{\circ}\right) \&$ (b) $H$ - plane $\left(\mathrm{Phi}=90^{\circ}\right)$ and Antenna B (c) E- plane $\left(\mathrm{Phi}=0^{\circ}\right) \&(\mathrm{~d}) H$ - plane $\left(\mathrm{Phi}=90^{\circ}\right)$ 


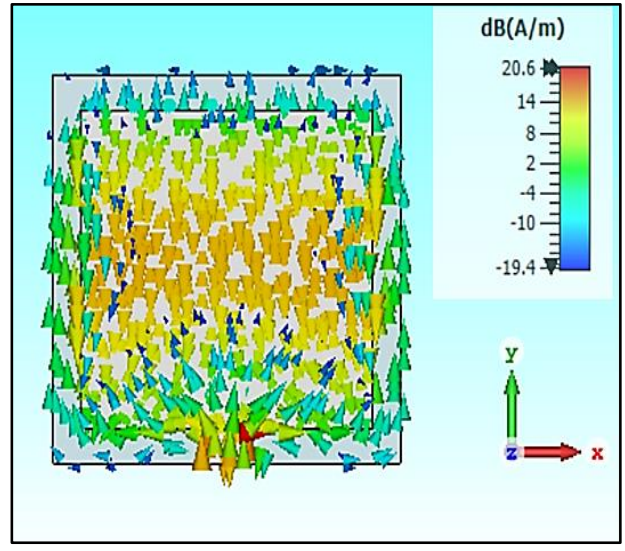

(a)

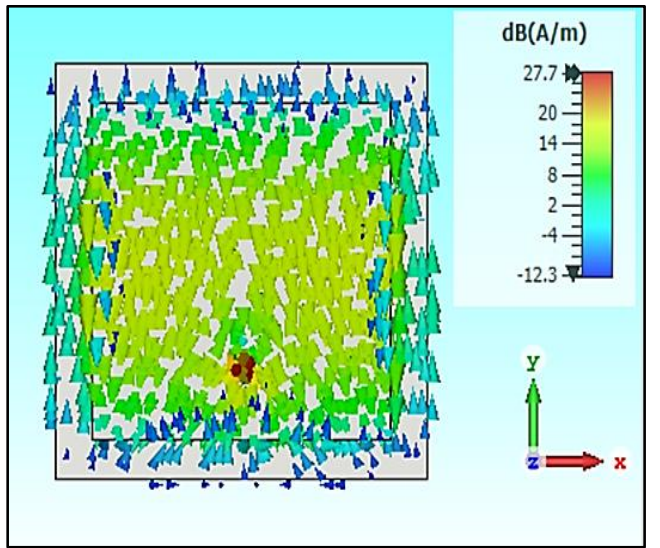

(b)

Figure 10. Surface current distribution of simulated result for (a) Antenna A (b) Antenna B

Figure 10 shows the surface current distribution of Antenna B which is higher in value as compared to Antenna A. With the improvement of $34 \%$ from $20.6 \mathrm{~dB}(\mathrm{~A} / \mathrm{m})$ of Antenna A in Antenna B, this is mainly due to the coaxial feed structure itself whereby the inner pin of a coaxial feed line penetrates the substrate.

\subsection{Comparative Analysis}

Table 2 summarised the simulated results of this work for these two feeding techniques of microstrip line feed (Antenna A) and coaxial feed (Antenna B).

Table 2. Simulated results of Antenna A \& Antenna B

\begin{tabular}{|l|c|c|}
\hline Parameter & Antenna A & Antenna B \\
\hline Return Loss, $\mathrm{S}_{11}(\mathrm{~dB})$ & -12.42 & -20.41 \\
\hline Realized Gain $(\mathrm{dBi})$ & 2.87 & 4.44 \\
\hline Bandwidth $(\mathrm{MHz})$ & 68.2 & 68.3 \\
\hline VSWR $(\mathrm{V})$ & 1.69 & 1.21 \\
\hline Directivity, E-plane (dBi) & 7.15 & 8.66 \\
\hline Efficiency (\%) & 36 & 38 \\
\hline Front-to-Back Ratio, FTBR (dBi) & 18.85 & 20.36 \\
\hline
\end{tabular}

From the table shown, the higher the return loss of Antenna B is illustrated as compared to Antenna B. This shows that the performance in Antenna A is far off better than Antenna A as a higher result in the negative return loss indicates a lesser reflection in the antenna. From the 
observation of return loss values too, the assessment of efficiency and performance can be compared and further evaluated.

Here, the simulated result shown that the total efficiency of $38 \%$ is obtained in Antenna B while Antenna A is having $36 \%$ of total efficiency. Due to the advantages of coaxial probe-feeding itself, a less spurious radiation in the back region is demonstrated as less signal is reflected in the antenna; therefore, has improved the efficiency of Antenna B. With the front-to-back-ratio (FTBR) of $20.36 \mathrm{dBi}$ in Antenna B in the E-field, this value is considered as good in antenna performance as it exceeds FTBR $>20 \mathrm{dBi}$ as compared to Antenna A that is $18.85 \mathrm{dBi}$.

Comparing the realised gain achieved in these two Antenna, Antenna B has demonstrated 50\% of lower gain differences as compared to Antenna B. This is due to the structure of coaxial probe-fed which perform a direct engagement with the patch. Therefore, the current distribution will be at the highest magnitude and concentration at the excitation port located at the back of the antenna. Due to this, the current flow will eventually be distributed evenly as it approaches the patch (Samat et. al, 2020). The rise in realised gain in Antenna B is expected as it demonstrated the higher efficiency which proven that gain $(G)$ is the product of the antenna efficiency $(\eta)$ and its directivity $(D)$ as per Equation 11.

$$
G=\eta \cdot D
$$

Meanwhile, the bandwidth of both antennas is showing a similar result. This shows that bandwidth parameter is not affected by the difference of feeding techniques as it is influenced by the thickness of the substrate used. Since Antenna A and Antenna B are using the same material of Felt, hence it has resulted an equal performance in both. As for Voltage Stand Wave Ratio (VSWR) both Antenna A and Antenna B shows a good performance when both values fall within 1 to 2 volts.

\section{Conclusion}

In this work, the performance of microstrip feedline and coaxial feed techniques is compared and investigated for textile antenna of GPS application. From the result presented, the coaxial feed technique is able to achieve a prominent high realised gain at $4.44 \mathrm{dBi}$ as compared to $2.87 \mathrm{dBi}$ in microstrip feedline. Meanwhile, the observation of other simulated results also shows that all parameters have performed better in the antenna using coaxial feed as compared to microstrip 
feedline. It can be concluded that it is very important to choose a suitable feeding method to ensure good performance in its efficiency, high bandwidth, and good radiation particularly in textile antenna application. Based on the justifications which are guided by the relevant theories, it can be stated that coaxial feed results give better performance as compared to microstrip feedline for the required parameters. Hence, the work proposed here for the textile antenna design using the coaxial feed techniques is suitable to to be integrated as part of clothing and further realised in GPS application.

\section{Acknowledgement}

The authors would like to thank the Faculty of Engineering, Built Environment and Information Technology (FoEBEIT), SEGi University and Antenna Research Centre (ARC), Faculty of Electrical Engineering, Universiti Teknologi MARA for supporting the research work.

\section{References}

Balanis, C. A. (2015). Antenna theory: analysis and design (3rd ed.). United States: John Wiley \& Sons.

Bisht, S., Saini, S., Prakash, V., \& Nautiyal, B. (2014). Study The Various Feeding Techniques of Microstrip Antenna Using Design and Simulation Using CST Microwave Studio. International journal of emerging technology and advanced engineering, 4(9), 318-324.

Del-Rio-Ruiz, R., Lopez-Garde, J.-M., \& Legarda, J. (2019). Planar Textile Off-Body Communication Antennas: A Survey. Electronics, 8(6), 714.

Kumar, A., Kaur, J., \& Singh, R. (2013). Performance analysis of different feeding techniques. International Journal of Emerging Technology and Advanced Engineering, 3(3), 884-890.

Mar Phyo, Z., May Nway, T., Kyu Kyu Win, K., \& Myo Tun, H. (2020). Development of Microstrip Patch Antenna Design for GPS in Myanmar. American Journal of Electromagnetics And Applications, 8(1), 1.

Mokal, M., Gagare, P., \& Labade, D. (2017). Analysis of Micro strip patch Antenna Using Coaxial feed and Micro strip line feed for Wireless Application. IOSR Journal Of Electronics And Communication Engineering, 12(03), 36-41.

Salvado, R., Loss, C., Gonçalves, R., \& Pinho, P. (2012). Textile materials for the design of wearable antennas: A survey. Sensors, 12(11), 15841-15857.

Samat, A., Zaidel, D., Mat, D., Sharip, M., Zaidel, D., Muhamad, I., \& Then, Y. (2020). Surface Current Distribution and Performance Analysis of Different Feeding Techniques for Microstrip Patch Antenna. 2020 13Th International UNIMAS Engineering Conference (Encon).

Shakhirul, M., Jusoh, M., Ismail, A., Kamarudin, M., Yahya, R., Yasin, M., \& Sabapathy, T. 
(2014). $1.575 \mathrm{GHz}$ Circular Polarization wearable antenna with three different substrate materials. 2014 IEEE Asia-Pacific Conference On Applied Electromagnetics (APACE).

Salonen, P., Rahmat-Samii, Y., Schaffrath, M., \& Kivikoski, M. (2004). Effect of textile materials on wearable antenna performance: a case study of GPS antennas. IEEE Antennas And Propagation Society Symposium, 2004.

Zaidi, N.I., Ali, M., Rahman, N., Nordin, M.S., Shah, A.A., Yahya, M.F., \& Yon, H. (2019). Analysis of Different Feeding Techniques on Textile Antenna. 2019 International Symposium on Antennas and Propagation (ISAP), 5-7. 